\title{
(6) BIOENG
}

\section{ACÚMULO DE NUTRIENTES E MASSA SECA PRODUZIDA POR Crotalaria juncea CULTIVADA NO CERRADO}

\author{
M. S. Silva ${ }^{1^{*}}$, G. R. F. Oliveira ${ }^{1}$, L. F. Merloti ${ }^{2}$, M. E. Sá ${ }^{1}$
}

${ }^{1}$ UNESP - Univ Estadual Paulista, FEIS, Campus de Ilha Solteira, SP, Brasil

${ }^{2}$ USP - Univ de São Paulo, CENA, Piracicaba, SP, Brasil

Article history: Received 12 January 2017; Received in revised form 20 February 2017; Accepted 21 February 2017; Available online 27 March 2017.

\section{RESUMO}

A adubação verde com Crotalaria juncea é uma estratégia vastamente utilizada no Cerrado para melhorar as características químicas, físicas e biológicas do solo, em uma matriz que apresenta limitações naturais para o desempenho adequado dos cultivos. O objetivo do trabalho foi de verificar o acúmulo de nutrientes e produção de matéria seca por $C$. juncea cultivada em solo de Cerrado. Dois experimentos foram realizados nos anos de 2015 e 2016, em um Latossolo Vermelho distrófico, no município de Selvíria, MS, Brasil. As semeaduras foram realizadas a lanço em área previamente preparada com aração e gradagem, sem utilização de adubação. Aos 80 dias após a semeadura e antes do pleno florescimento, as plantas foram manejadas com roçadora. Foram feitas as seguintes avaliações: (a) Massa seca: amostras obtidas de cada parcela foram levadas à estufa, realizou-se a mensuração da massa seca e o valor médio foi extrapolado para unidade de $\mathrm{kg} \mathrm{ha}^{-1}$. (b) Acúmulo de nutrientes: após coleta de amostras das plantas, determinou-se os teores de macro e micronutrientes e, posteriormente, multiplicou-se o teor de cada nutriente pela massa seca de $C$. juncea produzida, obtendo-se o acúmulo de macronutrientes $\left(\mathrm{g} \mathrm{kg}^{-1}\right)$ e micronutrientes $\left(\mathrm{mg} \mathrm{kg}^{-1}\right) . \mathrm{O}$ adubo verde apresentou elevada produção de matéria seca e excelente acúmulo de nitrogênio, potássio e ferro.

Palavras chave: reciclagem de nutrientes, adubação verde, prática conservacionista

\section{ACCUMULATION OF NUTRIENTS AND DRY MATTER PRODUCED BY Crotalaria juncea CULTIVED IN CERRADO}

\begin{abstract}
The green manuring with Crotalaria juncea is a strategy widely used in the Cerrado to improve the chemical, physical and biological characteristics of the soil, in a matrix that presents natural limitations to the proper performance of the crops. The objective of this work was to verify the accumulation of nutrients and dry matter production by $C$. juncea cultivated in Cerrado soil. Two experiments were carried out in the years 2015 and 2016, in a dystrophic Red Latosol, in the city of Selvíria, MS, Brazil. Seeds were insered in an area with conventional preparation, without the use of fertilization. At 80 days after sowing and before blooming, the plants were managed mechanically. The following evaluations were performed: (a) Dry matter production: the samples obtained from the plants were desiccated and the average dry matter yield was extrapolated to a unit of $\mathrm{kg} \mathrm{ha}^{-1}$. (b) Accumulation of nutrients: after collecting plant samples, the macronutrients and micronutrients contents were determined and, posteriorly, the content of each nutrient was multiplied by the dry mass of $C$.
\end{abstract}

\footnotetext{
*mssmarcio@yahoo.com
} 
juncea produced, obtaining the accumulation of macronutrients $\left(\mathrm{g} \mathrm{kg}^{-1}\right)$ and micronutrients $\left(\mathrm{mg} \mathrm{kg}^{-1}\right)$. The green manure presented high dry matter production and excellent accumulation of nitrogen, potassium and iron.

Keywords: nutrient recycling, green manure, conservationist practice

\section{INTRODUÇÃO}

O emprego de sistemas de produção intensivos no Cerrado tem contribuído para o aumento dos processos de degradação dos solos (SILVA et al., 2014), em uma matriz que, naturalmente, possui limitações para a produção agrícola devido à baixa fertilidade associada à elevada acidez, alta saturação por alumínio e baixa disponibilidade de fósforo (FERNANDES \& MURAOKA, 2002). Para atender a produtividade agrícola potencial das culturas, algumas medidas conservacionistas garantem a viabilidade da adequação desses solos para o crescimento e desenvolvimento adequado das plantas. Neste aspecto, a adubação verde é uma prática crucial para a região do Cerrado brasileiro (AMÁBILE et al., 2000), em razão desta medida melhorar as características físicas, químicas e biológicas do solo (CARVALHO et al., 1999; LEITE et al., 2010; CHAVES \& CALEGARI, 2001).

Diversos são os benefícios da adubação verde, tais como: proteção do solo contra erosão, aumento no teor de matéria orgânica do solo, melhoria na infiltração e retenção de água no solo, reciclagem de nutrientes e incorporação de $\mathrm{N}$ via associação simbiótica com microrganismos, redução de incidência de plantas daninhas por meio de liberação de substâncias alelopáticas e competição por luz, espaço, nutrientes e água (VON OSTERROHT, 2002 citado por RAGOZO et al., 2006).

Dentre as espécies utilizadas como adubo verde, a Crotalaria juncea apresenta grande potencialidade para uso no Cerrado, em razão da sua fitomassa permanecer por maior período em solos tropicais, devido à relação carbono/nitrogênio $\mathrm{C} / \mathrm{N}$ (29) ser superior à algumas leguminosas utilizadas (CARVALHO \& AMABILE, 2006), como o guandu (CALVO et al., 2010), Lablabe (CARNEIRO et al., 2008), feijão-de-porco e mucuna (ARAÚJO et al., 2011). A $C$. juncea apresenta grande aceitação pelos agricultores no planejamento da implementação do sistema de rotação de culturas, o que fundamenta a necessidade de estudos sobre o desempenho do adubo verde nas condições edafoclimáticas encontradas no Cerrado.

Alguns trabalhos atribuíram à $C$. juncea como uma espécie que apresenta elevada produtividade de matéria seca (MENEZES \& LEANDRO, 2004; COSTA et al., 2012; MENEZES et al., 2009; SORATTO et al., 2012) e alta eficiência no acúmulo de nitrogênio, cálcio, potássio e ferro (MENEZES \& LEANDRO, 2004), sendo que o potássio é prontamente disponível pela decomposição da palhada (COSTA et al., 2012; SORATTO et al., 2012), pelo fato desse nutriente não participar de compostos estruturais em plantas, facilitando a sua liberação para o solo (VIANA \& KIEHL, 2010) e, ou até mesmo por lixiviação do nutriente dos tecidos de plantas vivas (MORAES \& ARENS, 1969).

Como os solos de Cerrado, via de regra, apresentam baixa fertilidade natural (FERNANDES \& MURAOKA, 2002) e a adubação verde é uma prática conservacionista que condiciona melhorias nas características químicas, físicas e biológicas do solo (CARVALHO et al., 1999; LEITE et al., 2010; CHAVES \& CALEGARI, 2001), o presente trabalho teve como objetivo de verificar o acúmulo de nutrientes e produção de massa seca por C. juncea cultivada no cerrado. 


\section{MATERIAL E MÉTODOS}

Os experimentos foram realizados nos anos de 2015 e 2016, na área experimental da Faculdade de Engenharia de Ilha Solteira - UNESP, município de Selvíria, Mato Grosso do Sul, Brasil $\left(51^{\circ}\right.$ $22^{\prime} \mathrm{W}$ e $20^{\circ} 22^{\prime} \mathrm{S} ; 335 \mathrm{~m}$ de altitude). $\mathrm{O}$ solo é classificado como um Latossolo Vermelho distrófico (EMBRAPA, 2013). Antes da instalação dos experimentos foram coletadas amostras compostas de 20 subamostras, na camada de $0,0-0,2 \mathrm{~m}$, para a determinação das características químicas, realizadas de acordo com Raij \& Quaggio (1997) (Tabela 1). O clima, conforme a classificação de Köppen, é do tipo Aw, com média anual de $1.370 \mathrm{~mm}$. A temperatura média anual é de $23,5^{\circ} \mathrm{C}$ e a umidade relativa do ar está entre 70 e $80 \%$ (média anual) (CENTURION, 1982; INPE, 2016). Adicionalmente, foi feita avaliação periódica dos dados de temperatura e precipitação pluviométrica na área experimental, dados estes obtidos junto a estação meteorológica da Fazenda de Ensino, Pesquisa e Extensão (FEPE/UNESP) situada a $180 \mathrm{~m}$ da área experimental (Figura 1 e Figura 2).

As suplementações hídricas foram realizadas por meio de um sistema de irrigação convencional por aspersão com precipitação média de $3,0 \mathrm{~mm} \mathrm{~h}^{-1}$. No primeiro ano de cultivo foram feitas intervenções com irrigação entre 01/01 a 07/01, 08/01 a 14/01 e 15/01 a 21/01, com lâmina d'água aplicada de 17,0;22,0 e $10,0 \mathrm{~mm}$, respectivamente. No ano de 2016, a suplementação hídrica foi realizada entre 12/02 a 18/02 e 11/03 a 17/03, com lâmina d'água aplicada de 13,0 e 22,0 mm, respectivamente.

Tabela 1. Análise química do solo. Selvíria, Mato Grosso do Sul, Brasil, 2016.

\begin{tabular}{|c|c|c|c|c|c|c|}
\hline \multirow{2}{*}{$\begin{array}{l}\mathbf{P} \text { (resina) } \\
\mathrm{mg} \mathrm{dm}^{-3}\end{array}$} & \multirow{2}{*}{$\begin{array}{c}\text { MO } \\
\mathrm{g} \mathrm{dm}^{-3}\end{array}$} & \multirow[t]{2}{*}{ pH } & \multirow[t]{2}{*}{$\mathbf{K}$} & \multirow{2}{*}{\multicolumn{2}{|c|}{$\begin{array}{c}\mathbf{C a} \\
\ldots . . \mathrm{mmol}_{\mathrm{c}} \mathrm{dm}^{-3} \ldots \ldots . .\end{array}$}} & \multirow[t]{2}{*}{$\mathrm{H}+\mathrm{Al}$} \\
\hline & & & & & & \\
\hline 22 & 23 & 5,1 & 4,4 & 17 & 13 & 34 \\
\hline Al & SB & CTC & $\mathbf{V}$ & $\mathrm{Ca} / \mathrm{CTC}$ & Mg/CTC & $\mathbf{m}$ \\
\hline \multicolumn{2}{|c|}{$\ldots \ldots \mathrm{mmol}_{\mathrm{c}} \mathrm{dm}^{-3} \ldots \ldots \ldots$} & & & $\ldots . . \% \ldots \ldots .$. & & $\ldots$ \\
\hline 1 & 34,4 & 68,4 & 50 & 25 & 19 & 3 \\
\hline
\end{tabular}




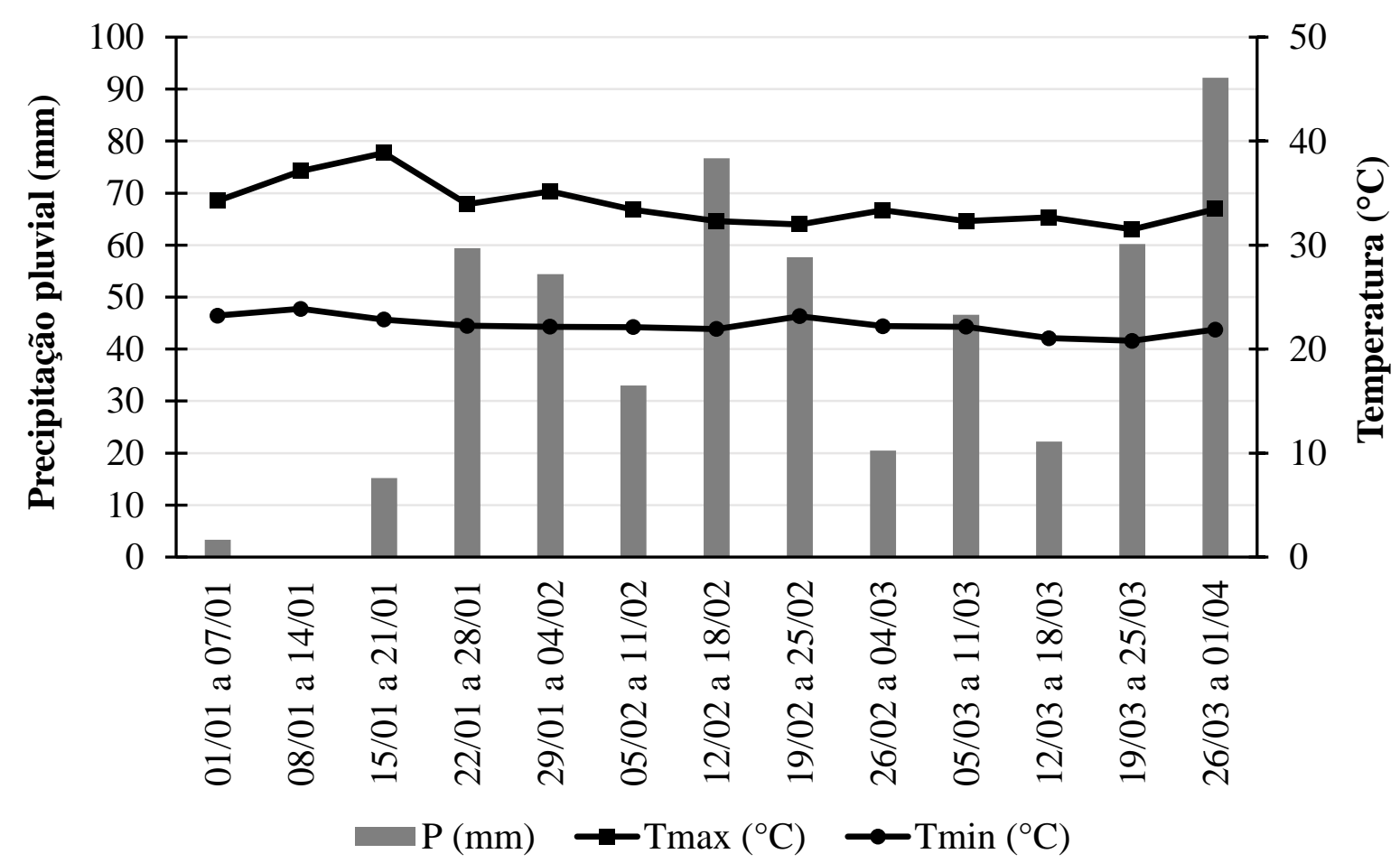

Figura 1. Precipitação pluvial (P), temperatura máxima (Tmáx) e temperatura mínima (Tmín) na área experimental, durante o período de condução do primeiro ano de cultivo. Selvíria, Mato Grosso do Sul, Brasil, 2015.

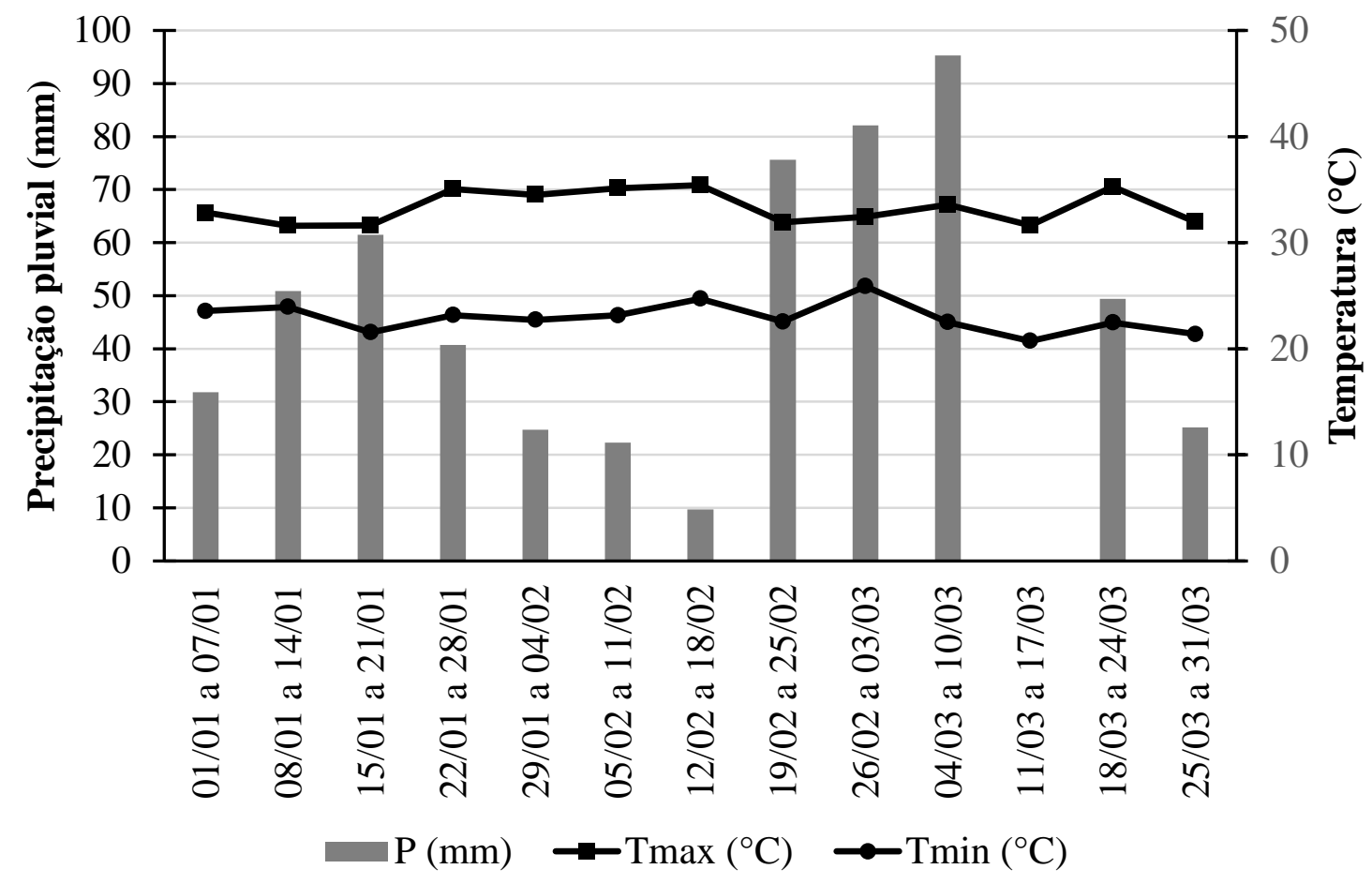

Figura 2. Precipitação pluvial (P), temperatura máxima (Tmáx) e temperatura mínima (Tmín) na área experimental, durante o período de condução do segundo ano de cultivo. Selvíria, Mato Grosso do Sul, Brasil, 2016.

O sistema de rotação de culturas foi adotado na área agrícola, sendo que em ambos anos experimentais a área ficou em pousio no outono e na estação seguinte a área foi ocupada com feijoeiro. $\mathrm{Na}$ primavera do primeiro e segundo ano 
agrícola foram cultivadas, respectivamente,

soja e milho (Tabela 2).

Tabela 2. Histórico de cultivo na área agrícola. Selvíria, Mato Grosso do Sul, Brasil, 2016.

\begin{tabular}{cllcc}
\hline $\begin{array}{c}\text { Ano } \\
\text { experimental }\end{array}$ & \multicolumn{3}{c}{ Estação } \\
\cline { 2 - 5 } & Outono & Inverno & Primavera & Verão \\
\hline $\mathbf{2 0 1 5}$ & Pousio & Feijão & Soja & Crotalária \\
$\mathbf{2 0 1 6}$ & Pousio & Feijão & Milho & Crotalária \\
\hline
\end{tabular}

As semeaduras de $C$. juncea foram realizadas a lanço em 06/01/2015 e 07/01/2016, visando uma população de 23.8000 plantas $\mathrm{ha}^{-1}$, em área previamente preparada com aração e gradagem, sem utilização de adubação. A área total foi dividida em 36 parcelas, constituídas por cinco linhas de $5 \mathrm{~m}$, sendo consideradas, como área útil, as três linhas centrais, desprezando-se $0,50 \mathrm{~m}$ em ambas as extremidades $\left(4,20 \mathrm{~m}^{2}\right)$.

Em 28/03/2016 e 29/03/2016, 80 dias após a semeadura e antes do pleno florescimento, as plantas de cobertura foram manejadas com roçadora.

Foram feitas as seguintes avaliações: (a) Produção de massa seca: anterior ao manejo das plantas, foram retiradas uma amostra de cada parcela para determinação da massa seca. As amostras das plantas foram obtidas de uma subárea $\left(0,25 \mathrm{~m}^{2}\right)$ da área útil da parcela. Posteriormente, as plantas foram acondicionadas em sacos devidamente identificados e o material foi mantido na estufa de ventilação forçada a $65{ }^{\circ} \mathrm{C}$ até atingir massa constante. Em seguida, determinou-se a massa de matéria seca média produzida e a mesma foi extrapolada para $\mathrm{kg} \mathrm{ha}^{-1}$. (b) Acúmulo de nutrientes: após a determinação da massa de matéria seca, as amostras foram

\section{RESULTADOS E DISCUSSÃO}

A produtividade de matéria seca de C. juncea foi muito elevada em ambos os anos experimentais, sendo o primeiro ano homogeneizadas e de cada amostra foi retirada uma subamostra, sendo posteriormente moídas em moinho tipo Wiley. As amostras destinadas à determinação do nitrogênio foram submetidas à digestão sulfúrica, sendo este determinado por calorimetria, usando o reagente de Nessler (JACKSON, 1958). Para determinação de $\mathrm{P}$ e $\mathrm{S}$, as amostras foram submetidas à digestão nítricoperclórica (JOHNSON \& ULRICH, 1959); com os extratos obtidos, determinou-se a concentração de $\mathrm{K}$, pelo método de fotometria de chama, e as concentrações de $\mathrm{Ca} \mathrm{e} \mathrm{Mg}$, por espectrofotometria de absorção atômica (MALAVOLTA et al., 1997). As amostras destinadas à determinação do $\mathrm{Zn}, \mathrm{Cu}$, Fe e $\mathrm{Mn}$ foram digeridas em mistura nítrico-perclórica (JOHNSON \& ULRICH, 1959). A seguir, o material foi analisado quimicamente, para determinação dos teores dos respectivos elementos, por espectrofotometria de absorção atômica (MALAVOLTA et al., 1997). Posteriormente, multiplicou-se o teor de cada nutriente pela massa seca de $C$. juncea produzida, obtendo-se a média do acúmulo de micronutrientes $\left(\mathrm{mg} \mathrm{kg}^{-1}\right) \mathrm{e}$ macronutrientes $\left(\mathrm{g} \mathrm{kg}^{-1}\right)$.

de cultivo com rendimento de $72,8 \%$ superior ao cultivo do ano seguinte (Tabela 3). 
Tabela 3. Massa seca produzida pela Crotalaria juncea. Selvíria, Mato Grosso do Sul, 2016.

\begin{tabular}{cc}
\hline $\begin{array}{c}\text { Ano de } \\
\text { cultivo }\end{array}$ & $\left.\begin{array}{c}\text { Massa seca } \\
\text {........ }\left(\mathbf{t ~ h a}^{-1}\right)\end{array}\right)$...... \\
\hline 2015 & 19,72 \\
\hline 2016 & 11,41 \\
\hline
\end{tabular}

Por se tratar de uma área em que se realiza rotação de culturas durante o ano todo, é bem provável que as culturas posteriores ao primeiro ano de cultivo tenham exportado grande quantidade de nutrientes, o que refletiu em um baixo aporte nutricional para o cultivo do adubo verde no segundo ano do experimento.

A produção de massa seca obtida foi muito superior aos encontrados por Alcântara et al. (2000) e Castro et al. (2005) em cultivo de verão, com valores de 6,5 t ha ${ }^{-1}$ e 7,69 $\mathrm{t} \mathrm{ha}^{-1}$, respectivamente. Embora a saturação por bases esteja abaixo do recomendado para a cultura (RAIJ et al., 1997), a espécie apresentou elevado desempenho agronômico, indicando a viabilidade do seu cultivo em áreas de fertilidade limitante.
A C. juncea apresentou elevada eficiência no acúmulo de nutrientes (Tabela 4), podendo suprir completamente e, ou parcialmente as exigências nutricionais das plantas que serão cultivadas posteriormente no sistema de rotação de culturas. Por ser uma leguminosa, o adubo verde se destacou como fonte importante para aumento de nitrogênio no solo, chegando a valores potenciais próximos a $400 \mathrm{~kg} \mathrm{ha}^{-1}$ (Figura 1). $\mathrm{O}$ efeito benéfico também foi constatado para incremento potencial de potássio no solo, com acúmulo de aproximadamente 400 e $200 \mathrm{~kg} \mathrm{ha}^{-1}$, no primeiro e segundo ano experimental, respectivamente (Figura 1).

Tabela 4. Teores de nutrientes em Crotalaria juncea. Selvíria, Mato Grosso do Sul, 2016

\begin{tabular}{|c|c|c|c|c|c|c|}
\hline Ano experimental & \multicolumn{6}{|c|}{ Teores de nutrientes } \\
\hline \multirow{6}{*}{2015} & \multicolumn{6}{|c|}{ …......................................................... $\mathrm{g} \mathrm{kg}^{-1}$} \\
\hline & $\mathbf{N}$ & $\mathbf{P}$ & $\mathbf{K}$ & Ca & Mg & $\mathbf{S}$ \\
\hline & 19,65 & 3,36 & 20,08 & 6,83 & 3,50 & 2,83 \\
\hline & \multicolumn{6}{|c|}{ 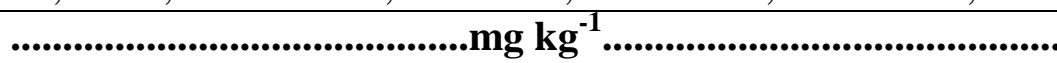 } \\
\hline & $\mathrm{Cu}$ & Fe & Mn & $\mathbf{Z n}$ & & \\
\hline & 33,33 & 946,67 & 75,01 & 32,00 & & \\
\hline \multirow{6}{*}{2016} & \multicolumn{6}{|c|}{ 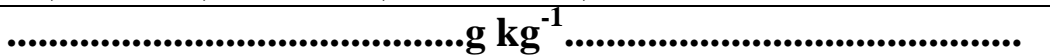 } \\
\hline & $\mathbf{N}$ & $\mathbf{P}$ & $\mathbf{K}$ & $\mathbf{C a}$ & Mg & $\mathbf{S}$ \\
\hline & 34,55 & 4,02 & 16,89 & 6,06 & 4,48 & 6,83 \\
\hline & \multicolumn{6}{|c|}{ 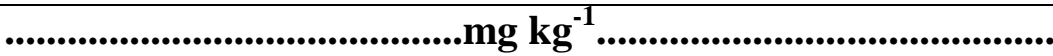 } \\
\hline & $\mathbf{C u}$ & $\mathbf{F e}$ & Mn & $\mathbf{Z n}$ & & \\
\hline & 14,00 & 381,02 & 82,05 & 28,03 & & \\
\hline
\end{tabular}




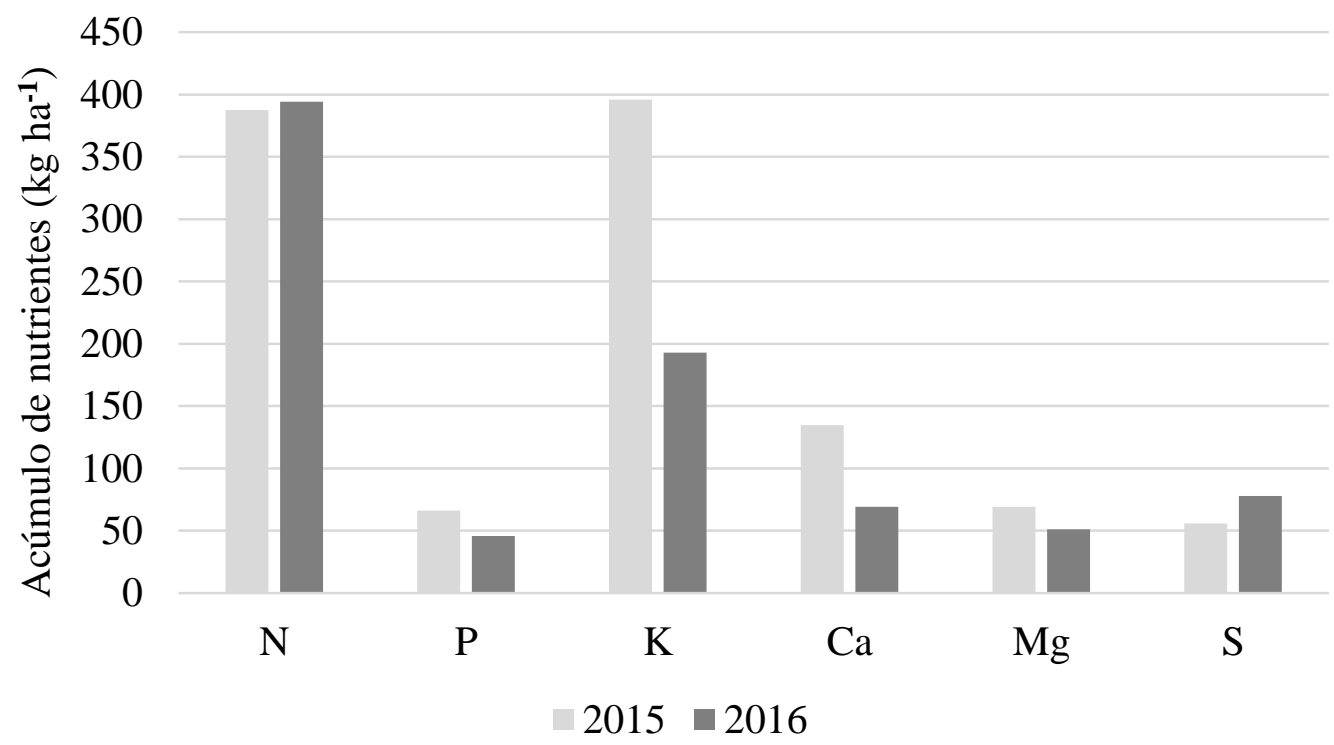

Figura 3. Acúmulo de macronutrientes obtidos pelo cultivo de Crotalaria juncea. Selvíria, Mato Grosso do Sul, 2016.

Em função da característica dos solos tropicais de possuir alto teor de ferro (SOUZA JUNIOR et al., 2010; SCHWERTMANN \& HERBILLON, 1992), a espécie apresentou maior acúmulo desse nutriente em razão da sua alta disponibilidade no solo. Os valores potenciais de micronutrientes que podem retornar ao sistema agrícola são substanciais, visto os elevados teores verificados em $C$. juncea (Figura 3), o que muitas vezes, variando conforme a cultura instalada na lavoura pode dispensar suplementação nutricional via fertilizante agrícola. A função de reduzir o uso de insumos agrícolas é uma das características mais importantes verificadas em áreas com uso de adubos verdes e, dessa forma, contribuindo significativamente para a sustentabilidade dos sistemas de produção agrícola (BERNARDES et al., 2010; LEITE et al., 2010).

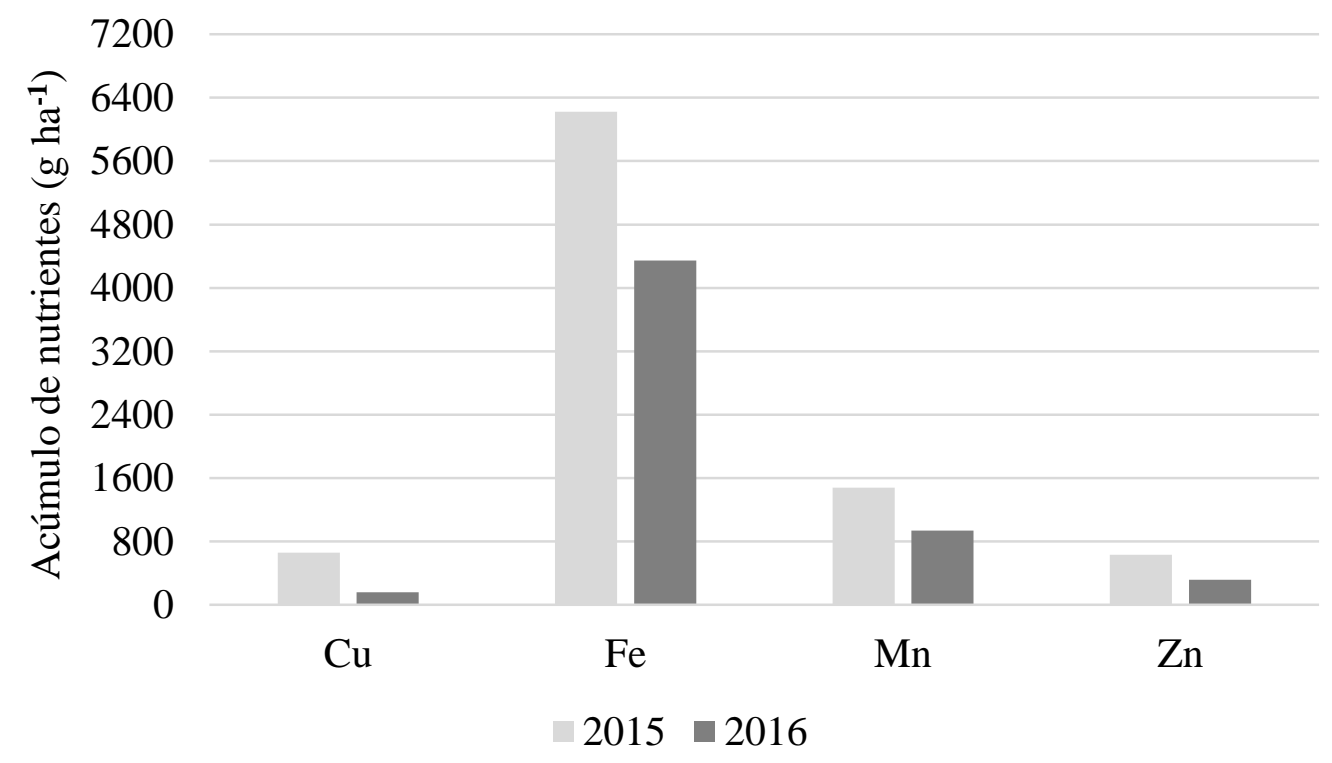

Figura 4. Acúmulo de micronutrientes obtidos pelo cultivo de Crotalaria juncea, Selvíria, Mato Grosso do Sul, 2016. 
Segundo Perin et al. (2004), a espécie além de contribuir com o aumento de $\mathrm{N}$ e $\mathrm{K}$ no solo, tem capacidade de reciclar eficazmente outros nutrientes para as culturas em sucessão ou rotação, como também evidenciado no presente trabalho (Figura 1 e Figura 2). Especificamente, o nitrogênio e o potássio são os nutrientes absorvidos em maior quantidade pelo feijoeiro (PEREZ et al., 2013), soja (CAIRES \& FONSECA, 2000), milho (BORGES, 2006), trigo (GARGANTINI et al., 1973), arroz (CRUSCIOL et al., 2003) e algodão (GARRIDO, 2009), o que fundamenta a compatibilidade do adubo verde com o cultivo precedente à instalação da maioria das culturas de relevância nacional. A palhada de $C$. juncea tem papel crucial para o incremento de nitrogênio e potássio no solo, com efeito positivo na produtividade dos cultivos (AMBROSANO et al., 2011; KAPPES et al., 2013; NOSSE et al., 2008; MELERO et al., 2013).

A espécie apresenta relação $\mathrm{C} / \mathrm{N}$ considerada média (29), isto é, valor próximo ao equilíbrio entre os processos de imobilização e mineralização (CARVALHO \& AMABILE, 2006; MONEGAT, 1991). Essa característica

\section{CONCLUSÃO}

O adubo verde em solo de Cerrado propicia boa cobertura de solo e excelente aporte nutricional, principalmente, com inerente à espécie a destaca dos demais adubos verdes, por apresentar capacidade de cobrir o solo por períodos consideráveis, aliado a liberação gradual de nutrientes via decomposição da matéria orgânica. Por outro lado, algumas espécies utilizadas como adubo verde apresentam lenta decomposição da palhada e, conseguinte, liberação de nutrientes, como: Pennisetum americanum (SILVA et al., 2005), Avena strigosa (AITA \& GIACOMINI, 2003), Urochloa brizantha e Urochloa ruziziensis (PACHECO et al., 2011), em razão da elevada relação $\mathrm{C} / \mathrm{N}$, sendo de 44,0; 40,0; 36,0 e 43,0 respectivamente. Conforme exposto, a relação $\mathrm{C} / \mathrm{N}$ difere entre as espécies vegetais, mas também varia em função do ponto de amostragem na planta (SILVA et al., 2008).

Embora seja recomendado realizar o manejo da $C$. juncea até no florescimento pleno (AMABILE et al., 2000; CARVALHO et al., 1999), resultados obtidos por Moraes et al. (2010) evidenciaram que o manejo das plantas no estádio de início de formação dos grãos, maximiza o potencial benéfico esperado da espécie como adubo verde.

nitrogênio, potássio e ferro para os cultivos posteriores.

\section{AGRADECIMENTO}

Ao CNPq pela concessão de bolsa de iniciação científica para o segundo e terceiro autor.

\section{REFERÊNCIAS BIBLIOGRÁFICAS}

AITA, C.; GIACOMINI, S. J. Decomposição e liberação de nitrogênio de resíduos culturais de plantas de cobertura de solo solteiras e consorciadas. Revista Brasileira de Ciência do solo, v. 27 (2): 601-612, 2003.
ALCÂNTARA, F.A.; FURTINI NETO, A.E.; DE PAULA, M.B.; MESQUITA, H.A.; MUNIZ, J.A. Adubação verde na recuperação da fertilidade de um Latossolo Vermelho-Escuro degradado. Pesquisa Agropecuária Brasileira, v.35 (2): 277288, 2000. 
AMABILE, R.F.; FANCELLI, A.L. \& CARVALHO, A.M. Comportamento de espécies de adubos verdes em diferentes épocas de semeadura e espaçamentos na região dos Cerrados. Pesquisa Agropecuária Brasileira, v.35 (2): 47-54, 2000.

AMBROSANO, E. J.; CANTARELLA, H.; AMBROSANO, G. M. B.; SCHAMMAS, E. A.; DIAS, F. L. F.; ROSSI, F.; TRIVELIN, P. C. O.; MURAOKA, T.; SACHS, R. C. C.; AZCÓN, R. Produtividade da cana-deaçúcar após o cultivode leguminosas. Bragantia, v.70 (4): 810-818, 2011.

ARAÚJO, E. S.; GUERRA, J. G. M.; ESPINDOLA, J. A. A.; URQUIAGA, S.; BODDEY, R. M.; MARTELLETO, L. A. P.; ALVES, B. J. R. Recuperação no sistema solo-planta de nitrogênio derivado da adubação verde aplicada à cultura do repolho. Pesquisa Agropecuária Brasileira, v. 46 (7):729-735, 2011.

BERNARDES, T. G.; SILVEIRA, P. M.; MESQUITA, M. A. M.; AGUIAR, R. A.; MESQUITA, G. M. Decomposição da biomassa e liberação de nutrientes dos capins braquiária e mombaça, em condições de cerrado. Pesquisa Agropecuária Brasileira, v. 40 (3): 370377, 2010.

BORGES, I. D. Marcha de absorção de nutrientes e acúmulo de matéria seca de milho. Tese (doutorado), UFLA, LavrasMG, 2006.

CALVO, C. L.; FOLONI, J. S. S.; BRANCALIÃO, S. R. Produtividade de fitomassa e relação $\mathrm{C} / \mathrm{N}$ de monocultivos e consórcios de guandu-anão, milheto e sorgo em três épocas de corte. Bragantia, v. 69 (1): 77-86, 2010.

CAIRES, E. F.; FONSECA. A. F. Absorção de nutrientes pela soja cultivada no sistema de plantio direto em função da calagem na superfície. Bragantia, v. 59 (2): 213-220, 2000.

CARNEIRO, M. A. C.; CORDEIRO, M. A. S.; ASSIS, P. C. R.; MORAES, M. A.; PEREIRA, H. S.; PAULINO, H. B.;
SOUZA, E. D. Produção de fitomassa de diferentes espécies de cobertura e suas alterações na atividade microbiana de solo de cerrado. Bragantia, v. 67 (2): 455-462, 2008.

CARVALHO, A.M. \& AMABILE, R.F. Cerrado: Adubação verde. Brasília, Embrapa Cerrados, 2006. 369p.

CARVALHO, A.M.; BURLE, M.L.; PEREIRA, J. \& SILVA, M.A. Manejo de adubos verdes no Cerrado. Embrapa Cerrados, 1999. 28p. (Circular Técnica, 4).

CASTRO, C.M. de, ALMEIDA, D.L. de; RIBEIRO, R.L.; CARVALHO, J.F. Plantio direto, adubação verde e suplementação com esterco de aves na produção orgânica de berinjela. Pesquisa Agropecuária Brasileira, v. 40 (5): 495-502, 2005.

CENTURION, J. F. Balanço hídrico da região de Ilha Solteira. Científica, v. 10 (1): 57-61, 1982.

CHAVES, J.C.D. \& CALEGARI, A. Adubação verde e rotação de culturas. Informações Agropecuárias, V. 22 (2): 53-60, 2001.

CRUSCIOL C. A. C.; ARF, O.; SORATTO R. P.; ANDREOTTI, M.; RODRIGUES, R. A. F. Absorção, exportação e eficiência de utilização de nutrientes pela cultura do arroz de terras altas em função de lâminas de água aplicadas por aspersão. Acta Scientiarum: Agronomy. v. 25 (2): 97-102, 2003.

COSTA, C. H. M.; CRUSCIOL, C. A. C.; SORATTO, R. P.; FERRANI NETO, J. Persistência e liberação de macronutrientes e silício da fitomassa de crotalária em função da fragmentação. Bioscience Journal, v. 28 (3): 384-394, 2012.

EMBRAPA - EMPRESA BRASILEIRA DE PESQUISA AGROPECUÁRIA (2013) Sistema brasileiro de classificação de solos. $3^{a}$ ed. Brasília, Embrapa. 353p

FERNANDES, C.; MURAOKA, T. Absorção de fósforo por híbridos de milho cultivados em solo de cerrado. Scientia Agricola, v.59 (4): 781-787, 2002. 
GARRIDO, M. S.; MENEZES, R. S. C.; SAMPAIO, E. V. S. B.; MARQUES, T. R. R. Crescimento e absorção de nutrientes pelo algodoeiro e pela mamoneira adubados com gliricídia e esterco. Revista Brasileira de Engenharia Agrícola e Ambiental, v.13 (5): 531-536, 2009.

GARGANTINI, H.; BLANCO, H. G.; HAAG, H. P.; MALAVOLTA, E. Absorção de nutrientes pelo trigo. Bragantia, v. 32 (16): 285-306, 1973.

INPE - Instituto Nacional de Pesquisas Espaciais (2016). Previsão de tempo para cidades. Disponível em: $<$ http://www.cptec.inpe.br/cidades/estendid a/5123>. Acessado em: 15 de outubro de 2016.

JACKSON, M. L. Soil chemical analysis. Englewood Cliffs: Prentice-Hall, 1958. $458 \mathrm{p}$.

JOHNSON, C. M.; ULRICH, A. Analytical methods for use in plants analyses. Los Angeles: University of California, 1959. p. 32-33. (Bulletin, 766).

KAPPES, C.; ARF, O.; ANDRADE, J. A. C. Produtividade do milho em condições de diferentes manejos do solo e de doses de nitrogênio. Revista Brasileira de Ciência do Solo, v. 37 (3) :1310-1321, 2013.

LEITE, L.F.C.; FREITAS, R.C.A.; SAGRILO, E. \& GALVÃO, S.R.S. Decomposição e liberação de nutrientes de resíduos vegetais depositados sobre Latossolo Amarelo no Cerrado Maranhense. Revista Ciência Agronômica, v. 41 (2) :29-35, 2010.

MALAVOLTA, E.; VITTI, G. C.; OLIVEIRA, S. A. Avaliação do estado nutricional das plantas: princípios e aplicações. 2.ed. Piracicaba: Potafos, 1997. 319 p.

MELERO, M. M.; GITTI, D. C.; ARF, O.; RODRIGUES, R. A. F. Coberturas vegetais e doses de nitrogênio em trigo sob sistema plantio direto. Pesquisa
Agropecuária Tropical, v. 43 (4): 343353, 2013.

MENEZES, L. A. S.; LEANDRO, W. M. Avaliação de espécies de coberturas do solo com potencial de uso em sistema de plantio direto. Pesquisa Agropecuária Tropical, v. 34 (3): 173-180, 2004.

MENEZES, L. A. S.; LEANDRO, W. M.; OLIVEIRA JUNIOR, J. P. de; FERREIRA, A. C. B.; SANTANA, J. das G.; BARROS, R. G. Produção de fitomassa de diferentes espécies, isoladas e consorciadas, com potencial de utilização para cobertura do solo. Bioscience Journal, v. 25 (2): 7-12, 2009.

MONEGAT, C. Plantas de cobertura do solo: Características e manejo em pequenas propriedades. Chapecó: Ed. do autor, 1991. p. 337.

MORAES, J.A.P.; ARENS, K. Eliminação de potássio pelas folhas em dependência da luz e obscuridade (Nota preliminar). Ciência e Cultura, v. 21 (2) :728-730, 1969.

MORAES, R. M.; PADOVAN, M. P.; MOTTA, I. S.; HERNANI, L.C.; SOUZA, M. T.; OLIVEIRA, F. L.; SILVA, E. E. Acúmulo de massa seca e nutrientes na parte aérea do milheto e o estádio mais adequado de manejo para fins de adubação verde. Revista Brasileira de Agroecologia, v. 3 (2): 95-98, 2008.

NOSSE, T. O.; AQUINO, S. S.; CAZETTA, D. A.; ARF, O.; CASSIOLATO, A. M. R. Restos vegetais e adubação nitrogenada na micorrização e produtividade do arroz de terras altas em sistema plantio direto. Acta Scientiarum: Agronomy. v. 30 (4): 547-553, 2008.

PACHECO, L. P.; LEANDRO, W. M.; MACHADO, P. L. O. A.; ASSIS, R. L.; COBUCCI, T.; MADARI, B. E.; PETTER, F. A. Produção de fitomassa e acúmulo e liberação de nutrientes por plantas de cobertura na safrinha. Pesquisa Agropecuária Brasileira, v. 46 (1): 17-25, 2011. 
PERIN, A.; SANTOS, R.H.S.; URQUIAGA, S.C.; GUERRA, J.G.M. \& CECON, P.R. Produção de fitomassa, acúmulo de nutrientes e fixação biológica de nitrogênio por adubos verdes em cultivo isolado e consorciado. Pesquisa Agropecuária Brasileira, v. 39 (2): 35-40, 2004.

PEREZ, A. A. G.; SORATTO, R P.; MANZATTO N. P.; SOUZA, E. F. C. Extração e exportação de nutrientes pelo feijoeiro adubado com nitrogênio, em diferentes tempos de implantação do sistema Plantio direto. Revista Brasileira de Ciência do Solo, v. 37 (2): 1276-1287, 2013.

RAGOZO, C. R. A.; LEONEL, S.; CROCCI, A. J. Adubação verde em pomar cítrico. Revista Brasileira de Fruticultura, v. 28 (1): 69-72, 2006.

RAIJ, B. van; CANTARELLA, H.; QUAGGIO, J.A.; FURLANI, A.M.C. (Ed.). Recomendações de adubação e calagem para o Estado de São Paulo. 2.ed. rev. e atual. Campinas: Instituto Agronômico/Fundação IAC, 1997. 285p. (Boletim Técnico, 100).

SCHWERTMANN, U.; HERBILLON, A.J. Some aspects of fertility associated with the mineralogy of highly weathered tropical soils. In: LAL, R.; SANCHEZ, P. Myths and Science of soils of the tropics. Madison, Soil Science Society America, 1992. p.47-59. (Special Publ. n.29).

SILVA, J.E.; LEMAINSKI, J. \& RESK, D.V.S. Perdas de matéria orgânica e suas relações com a capacidade de troca catiônica em solos da região de Cerrados do oeste baiano. Revista Brasileira de Ciência do Solo, v. 18 (3): 541-547, 1994.

SILVA, E. C.; MURAOKA, T.; BUZETTI, S.; VELOSO, M. E. C.; TRIVELIN, P. C. O. Aproveitamento do nitrogênio $\left({ }^{15} \mathrm{~N}\right)$ da crotalária e do milheto pelo milho sob plantio direto em Latossolo Vermelho de Cerrado. Ciência Rural, v. 32 (3): 739-746, 2006.

SILVA, E. C.; MURAOKA, T.; BUZETTI, S.; ESPINAL, F. S. C.; TRIVELIN, P. C. O. Utilização do nitrogênio da palha de milho e de adubos verdes pela cultura do milho. Revista Brasileira de Ciência do Solo, v. 32 (2): 2853-2861, 2008.

SORATTO, R. P.; CRUSCIOL, C. A. C.; COSTA, C. H. M.; FERRANI NETO, J.; CASTRO, G. S. A. Produção, decomposição e ciclagem de nutrientes em resíduos de crotalária e milheto, cultivados solteiros e consorciados. Pesquisa Agropecuária Brasileira, v.47 (10): 14621470,2012

SOUZA JUNIOR, I. G.; COSTA, A. C. S.; VILAR, C. C.; HOEPERS, A. Mineralogia e susceptibilidade magnética dos óxidos de ferro do horizonte B de solos do Estado do Paraná. Ciência Rural, v.40 (3): 513-519, 2010.

VIANA, E. M.; KIEHL, J. C. Doses de nitrogênio e potássio no crescimento do trigo. Bragantia, v. 69 (4): 975-982, 2010. 